\title{
Atmospheric Nutrient Input to the Baltic Sea from 1850 to 2006: A Reconstruction from Modeling Results and Historical Data
}

\author{
Tuija Ruoho-Airola, Kari Eilola, Oleg P. Savchuk, \\ Maija Parviainen, Virpi Tarvainen
}

\begin{abstract}
In this study, a consistent basin-wise monthly time series of the atmospheric nutrient load to the Baltic Sea during 1850-2006 was compiled. Due to the lack of a long time series (1850-1960) of nutrient deposition to the Baltic Sea, the data set was compiled by combining a time series of deposition data at the Baltic Nest Institute from 1970 to 2006, published historical monitoring data and deposition estimates, as well as recent modeled Representative Concentration Pathways (RCP) emission estimates. The procedure for nitrogen compounds included estimation of the deposition in a few intermediate reference years, linear interpolation between them, and the decomposition of annual deposition into a seasonal deposition pattern. As no reliable monitoring results were found for the atmospheric deposition of phosphorus during the early period of our study, we used published estimates for the temporal and spatial pattern of the phosphorus load.
\end{abstract}

Keywords Baltic Sea - Deposition · Historical · Nitrogen · Phosphorus

\section{INTRODUCTION}

Coupled physical and biogeochemical models are important tools to help understand the functioning of the Baltic Sea system. They can also be used to evaluate management measures, e.g., to reduce the negative impacts of eutrophication. The HELCOM Baltic Sea Action Plan (HELCOM 2007; Backer et al. 2010) is an example of how one model (Savchuk and Wulff 2007, 2009) was used to

Electronic supplementary material The online version of this article (doi:10.1007/s13280-012-0319-9) contains supplementary material, which is available to authorized users. stimulate discussions and support decisions by decision makers. However, the uncertainties regarding projected measures have increased because of the expected impacts of climate change. Therefore, several biogeochemical models, BAltic sea Long-Term large-Scale Eutrophication Model (BALTSEM), the Ecological Regional Ocean Model (ERGOM), and the Swedish Coastal and Ocean Biogeochemical model, coupled to the Rossby Centre Ocean circulation model (RCO-SCOBI), are currently being used in ensemble to estimate uncertainties originating from generalized descriptions of biogeochemical processes as well as from uncertain future climate change and socioeconomic developments in the countries surrounding the Baltic Sea (Meier et al. 2011, 2012).

Eilola et al. (2011) evaluated the performance of an ensemble including three Baltic Sea biogeochemical models for the period 1970-2005. The results were encouraging, but the model results were influenced by poorly known initial conditions in the early 1960s. A longer spin-up period is needed for the models due to the long water and nutrient residence times in the semienclosed Baltic Sea. In order to validate the capability of the models to correctly simulate nutrient cycling and oxygen dynamics under different climate conditions and human activities, the model simulations must therefore begin from a trophic state corresponding to a significantly lower anthropogenic impact than today. The situation in the 1850s was arguably even more pristine than the preindustrial conditions discussed by Savchuk et al. (2008), and was selected as the starting point of the historical model runs. However, in order to achieve reliable and reproducible results, the forcing of the models has to be well described. The aim of the present work was therefore to create a realistic time series of atmospheric nutrient loads to the Baltic Sea from 1850 to 2006. 
The atmospheric load of inorganic nitrogen compounds to the Baltic Sea has regularly been estimated by the Baltic Marine Environment Protection Commission (HELCOM) since 1987 (HELCOM 1987). At present, the assessments are based on the monitoring results and modeled estimates of the Cooperative Programme for Monitoring and Evaluation of the Long-range Transmissions of Air Pollutants in Europe (EMEP) (e.g., Bartnicki et al. 2008). Long-term trends in nitrogen deposition have been estimated for areas contributing substantially to the atmospheric load to the Baltic Sea in earlier studies (e.g., Brimblecombe and Stedman 1982; Asman et al. 1988; Schöpp et al. 2003; Fowler et al. 2004). However, there is still a need for a consistent long-term trend for the atmospheric nutrient deposition focusing directly on the Baltic Sea. In this work, we present a unique combination of historical records of atmospheric nitrogen deposition compiled from published data and results from recent model reconstructions of historical nitrogen emissions. Due to insufficient monitoring results, the reconstruction of phosphorus deposition is based on published estimates.

\section{MATERIALS AND METHODS}

The reconstruction of the deposition data set for 1850-2006 began with the 1970-2006 monthly deposition data set compiled at the Baltic Nest Institute (Gustafsson et al. 2012). For the time period 1850-1970, the procedure included the estimation of all important parameters for total inorganic nitrogen deposition (oxidized and reduced nitrogen, fractions of dry and wet deposition and the seasonal pattern) for six selected reference years: 1850, 1900, 1925, 1950, 1960, and 1970. The deposition parameters at these reference years were estimated with the help of historical data and emission data scenarios. Furthermore, a linear interpolation of annual integrals between the reference years was performed in relative units corresponding to a fraction of the deposition in 1970. Thus, quantitative continuity between past and contemporary deposition was ensured. Finally, the average seasonal deposition pattern estimated from the 1970-2006 monthly time series was extended backwards to cover the entire time period 1850-1970.

We decided to strive for a generalized representation of the deposition of nitrogen species in 1850-1970, which would describe the development in the geographic area, highly influencing the airborne load to the Baltic Sea. Important source areas for the atmospheric load to the Baltic Sea, in addition to the Baltic Sea countries, include Great Britain, France, the Netherlands and the international shipping traffic in the Baltic Sea and North Sea (Bartnicki et al. 2011). At present, Germany, Poland, and Denmark contribute most to the nitrogen load to the Baltic Sea. The data provided by the literature offered no possibility for a smaller scale analysis, especially not for the separate basins of the Baltic Sea. We had to rely on published historical data as the best available source of knowledge, despite uncertainties in the reliability of the data. However, the usefulness of part of the historical data has been studied before, and is also discussed below.

In the following, the information sources used for reconstructing the data set and the detailed steps of the procedure are introduced.

\section{Modeled Nitrogen Deposition Estimates Offer a Starting Point}

Our reconstruction of the 1850-2006 data set started with the compilation of atmospheric inorganic nitrogen deposition at the Baltic Nest Institute (Gustafsson et al. 2012) from estimates obtained by Granat (2001) and from simulations by the Cooperative Programme for Monitoring and Evaluation of the Long-range Transmissions of Air Pollutants in Europe (EMEP, see e.g., Bartnicki et al. 2008). The data produced by Granat are available in the Baltic Environment Database (BED) as monthly mean wet and dry depositions of reduced and oxidized nitrogen from 1970 to 1991 with a spatial resolution of $1^{\circ} \times 1^{\circ}$ squares for the entire Baltic Region. The EMEP annual depositions of the same four components for 1980, 1985, 1990, 1995-2006 with a resolution of $50 \times 50 \mathrm{~km}$ are available through the "EMEP data" module of the Decision Support System Nest (DSS Nest). For the reconstruction of continuous 1970-2006 monthly time series, both BED and EMEP data were first appropriately interpolated and integrated over thirteen sub-basins of the Baltic Sea in the BALTSEM model (BALTSEM basins) (see e.g., Gustafsson et al. 2012). Next, integrated monthly time series for 1986-1990 from BED were used to reconstruct basin-specific seasonal patterns in the form of 12 monthly dimensionless fractions of annual integrals. Finally, these patterns were used as multiplication factors to decompose annual EMEP integrals into monthly time series, and a gap from 1992 to 1994 was filled with data from HELCOM (1997).

The spatial variation in the average deposition of reduced and oxidized nitrogen at the end point of our time series is illustrated in Fig. 1. The annual 5-year running mean over the period 1980-2006 was quite similar in all basins. No large changes appeared in the atmospheric circulation, with dominant westerly winds over Fennoscandia during 1890-2000 (Moberg et al. 2005), and the hot spots of total nitrogen deposition were the same in 1860 and 1990 (Galloway et al. 2004).We therefore assume similar trends in all basins for the period 1850-2006, and the same compilation of the relative changes (compared to 1970 

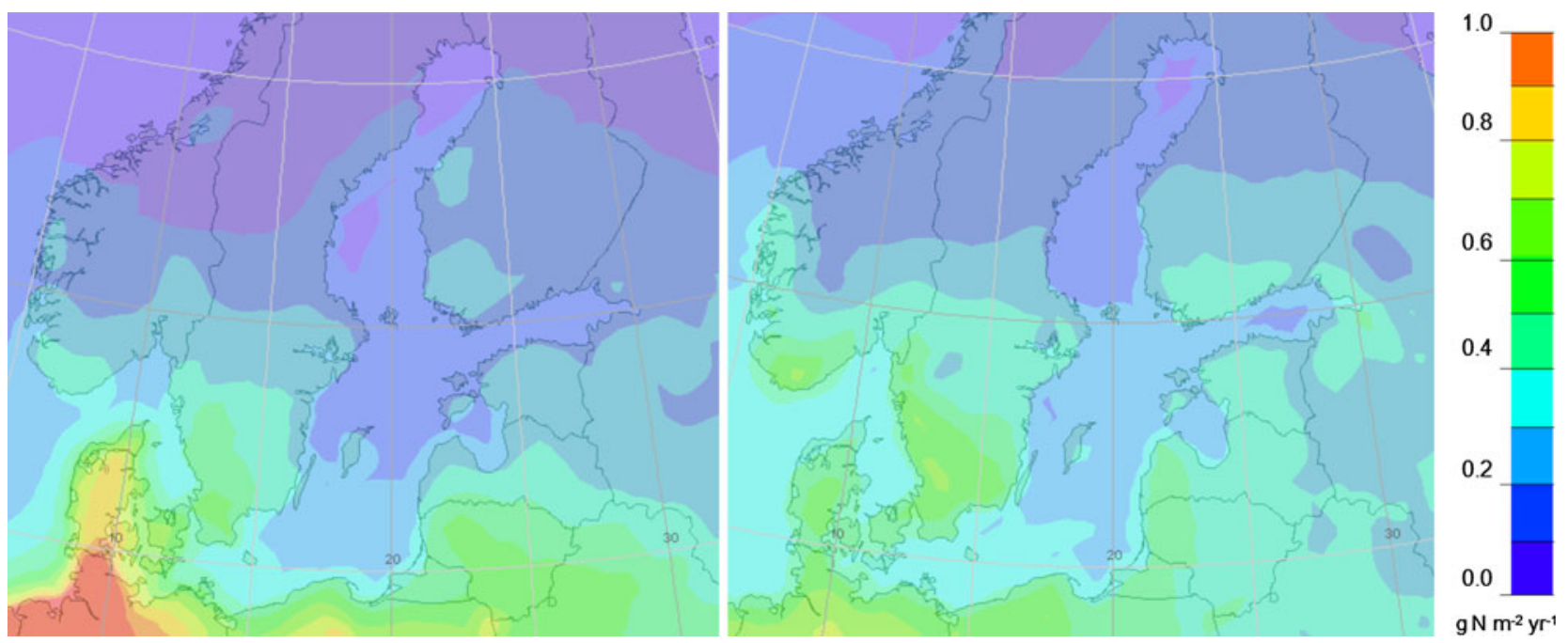

Fig. 1 Average annual deposition of reduced (left) and oxidized (right) inorganic nitrogen over the Baltic Sea region in 2000-2006. The maps were prepared within DSS Nest from the data available via the EMEP website (Bartnicki and Valiyaveetil 2008)

values) was applied for the whole Baltic Sea. Likewise, we assume no large changes to have occurred in the seasonal variation in deposition, and the seasonal cycle was evaluated from Baltic Nest Institute data for 1970-2006.

Granat (2001) calculated gridded $\left(1^{\circ} \times 1^{\circ}\right)$ monthly deposition estimates for the inorganic nitrogen species covering the whole Baltic Sea for 1970-1991. He based the estimate of wet deposition on precipitation chemistry data from stations around the Baltic Sea belonging to international (EMEP, HELCOM) and Swedish national (PMK) networks and precipitation fields. For quality assurance, the monthly data from each station were screened against both the normal conditions at the location and values from nearby stations, and outliers were removed. The quality controlled data were then interpolated by distance-weighting functions between all the stations in a grid. For periods with fewer measurements, the deposition at each grid point was estimated by interpolation from the average of the measured deposition, the seasonal variation and trend. The gridded dry deposition of nitrogen compounds based on interpolated air concentrations of nitrogen compounds from stations in international (EMEP, HELCOM) and national (Swedish and Danish) networks and on deposition velocities published by Lindfors et al. (1991, 1993). Granat (2001) compared the calculated gridded monthly dry and wet depositions of nitrate, ammonia, and ammonium with measured values and other published estimates, and evaluated the uncertainties. The agreement between measured and interpolated values was satisfactory, the mean deviation for open sea stations being about $10 \%$. Granat's estimate for deposition differed between 10 and $25 \%$ from the EMEP estimate, depending on the component and sub-basin.

\section{Availability of Historical Data}

We examined published data on the atmospheric concentration and deposition of nutrients from almost 200 stations in the geographic area from where emissions substantially influence the nutrient input to the Baltic Sea. The time period covered was from 1850 to approximately 1970 . The majority of the publications provide data on the precipitation of inorganic nitrogen compounds, nitrate and ammonium. Only a few measurements of gaseous and particulate nitrogen compounds were found, and none for atmospheric phosphorus. The articles that covered the beginning of the study period mostly included measurements from one or a few locations, often agricultural research stations. The concentration or deposition data from these stations mainly covered short periods, from months to a couple of years. Deposition was first determined from simultaneous measurements at many stations in the 1950s. Figure S1 in Electronic Supplementary Material illustrates the spatial coverage of precipitation chemistry measurements in publications from different periods. In addition to articles including observations, valuable reviews of older measurements have been published. Thorough investigations of early air and precipitation quality measurements have been prepared by Miller (1905), Russell and Richards (1919), Eriksson (1952), and Sutton et al. (2008).

\section{Core Data Set of Historical Measurements}

Data covering longer periods, repeated measurements from the same locations and measurements at stations situated near the coast of the Baltic Sea were the most relevant for our work and were thus examined in detail when estimating 
Fig. 2 Annual nitrate and ammonium deposition in precipitation at Rothamsted between 1853 and 1984. Data from Miller (1905), Russell and Richards (1919), and Goulding et al. (1986)

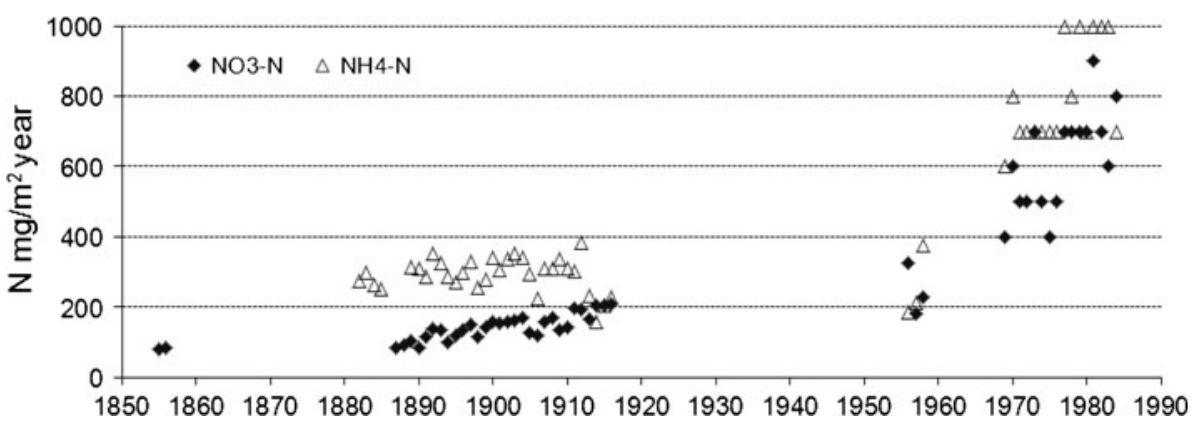

the development in nitrogen deposition. Table S1 (Electronic Supplementary Material) lists these stations with their coordinates, the first and last year of published data, and references to the articles. The locations of the stations are marked in Figure S1 (Electronic Supplementary Material), and the name of each station is presented in the time period when monitoring first started. The oldest stations were located using the original publications containing the data, present day names of the sampling stations, and historical documents about the old research stations.

The most extensive historical observations of nitrate and ammonium in precipitation were performed at the Rothamsted Experimental Station in southern England, where published measurements cover the years 1853-1856, 1876-1916, 1955-1966, and 1969-1984 (for references, see Table S1, Electronic Supplementary Material). The development of nitrogen deposition recorded at Rothamsted is highly valid for the atmospheric load of oxidized nitrogen to the Baltic Sea, because the UK is among the most important emission sources of the atmospheric nitrogen load to the Baltic Sea (Bartnicki et al. 2011). According to EMEP-W calculations, the UK was ranked as the second largest contributor to oxidized nitrogen deposition, the ninth for reduced nitrogen and the fourth for total nitrogen deposition to the Baltic Sea in the 10-year period from 1997 to 2006 (Bartnicki et al. 2011). The relevance of the development recorded at Rothamsted is further justified by the high correlation $\left(R^{2}=0.68\right)$ between $\mathrm{NO}_{x}$ deposition at Rothamsted and that over the Gotland Sea simulated by EMEP for 1980, 1985, 1990, and 1995-2006. For the deposition of reduced nitrogen, no correlation between the Rothamsted and Baltic Proper data was found in this study. Thus, from the Rothamsted data, only the changes in the nitrate deposition were applied in the reconstruction of our data set.

Data on the deposition of ammonium and nitrate at Rothamsted from 1853 to 1966 have been analyzed by Brimblecombe and Pitman (1980). They suggest that the collection procedures through the time period are intercomparable and that the changes in the nitrate time series are consistent with the general development of the emission sources (Brimblecombe and Pitman 1980). It is not usually possible to accurately determine the quality of historical deposition data, because exact descriptions of sampling and analytical methods are missing from the publications. Positive evidence of the reliability of the Rothamsted data includes the use of Kjeldahl's analytical method (Brimblecombe and Pitman 1980), which is still valid.

The wet deposition of nitrate in Rothamsted increased at least fivefold between the 1850s and 1980s (Fig. 2). The deposition was less than $100 \mathrm{mg} \mathrm{m}^{-2}$ in the $1850 \mathrm{~s}$ and steadily increased to the level of $200-300 \mathrm{mg} \mathrm{m}^{-2}$ in the $1950 \mathrm{~s}$, and further to a mean level of at least $500 \mathrm{mg} \mathrm{m}^{-2}$ in the 1980s.

In the core data set, in the 1950s and 1960s, a dense network of measuring stations was operating within the European Air Chemistry Network (EACN). Common methods were adopted by the EACN (Egnér and Eriksson 1955). During 1956-58, measurements were taken at over 100 stations, and some stations continued monitoring in the 1960s. The activity of the EACN network has been described and the data published, for example, by Eriksson (1952), Anonymous (1955), Granat et al. (1977), and Granat (1978).

\section{Emission Estimates}

Recent reconstructions of historical emissions since 1850 are available in the Representative Concentration Pathways (RCP) database ${ }^{1}$ (Lamarque et al. 2010). The data, including the $\mathrm{NO}_{x}$ and $\mathrm{NH}_{3}$ emissions, are extensive and have undergone several procedures to ensure quality and consistency, to harmonize regional base-year emissions with recent inventories, and to downscale the projections to $0.5^{\circ} \times 0.5^{\circ}$ horizontal resolution (Langner et al. 2010). The historical reconstruction of each emitted compound, for each region and sector, is forced to agree with the 2000 estimate, ensuring continuity between past and 2000 emissions. The Swedish Meteorological and Hydrological Institute (SMHI) has processed the RCP data for the European domain (Langner et al. 2010). The emission

\footnotetext{
${ }^{1} \mathrm{http} / / /$ www.iiasa.ac.at/web-apps/tnt/RcpDb.
} 
values of fields for a specific emission sector were aggregated over all months of a year and over the complete European domain, i.e., the sum of values in meridional and zonal directions. The complete time series of emissions for $1850-2000$ of the SMHI were utilized in our study.

\section{Estimation of N Deposition in the Reference Years}

The years $1850,1900,1925,1950,1960$, and 1970 were selected as reference years in the time series of the atmospheric nitrogen load. Firstly, the total nitrogen deposition in each decade was roughly estimated. For 1850, 1900, and 1925, especially data from Rothamsted and the other core stations greatly influenced the estimated deposition value. The RCP emissions were utilized when the final development in the deposition values between the reference years and the present day was adjusted. The western part of central Europe was estimated by Galloway et al. (2004) to have already received elevated loads of atmospheric nitrogen in 1860. This was taken into account in the application of the core historical data by excluding obvious hot spots.

For 1950 and 1960, the oxidized and reduced nitrogen deposition was mainly estimated from EACN data and the RCP emissions. The median of all the annual depositions monitored was considered to represent the typical level of deposition for each station. An inverse distance weighting (IDW) interpolation of the annual median values was performed over all 117 stations in the 1950s, and depositions allocated to the Baltic Proper were selected to represent the century in the general development of the nitrogen deposition to the Baltic Sea.

If the oxidized and reduced nitrogen depositions for the reference year could not be separately estimated, the estimate for total nitrogen deposition was split into these components based on their relatively constant ratio in historical data (Brimblecombe and Stedman 1982) and modeled estimates in the Baltic Nest Institute data from 1970 to 2006 (Savchuk et al. 2012). In addition, the core data on historical measurements mainly included only the wet deposition part of nitrogen. Thus, the amount of dry deposition was derived from modeled estimates in the Baltic Nest Institute data, using a wet/total factor of 0.7.

\section{Estimate of $\mathbf{P}$ Deposition}

Because no useful monitoring data were found for the atmospheric deposition of phosphorus (P) during the early part of our study period, we use published estimates for the temporal and spatial pattern of the P load. Historical estimates of the atmospheric deposition of phosphorus ranging from 5000 to 9000 ton year $^{-1}$ (Nehring and Wilde 1982; Larsson et al. 1985; HELCOM 1987, 1989; Davidavichiene and Sopauskiene 1989) were already comparable to the phosphorus input from land of about 40000 ton $\mathrm{P}_{\text {year }}{ }^{-1}$ (HELCOM 1987, 1993). Phosphorus deposition has so far not been included in HELCOM's pollution load compilations. However, since modeling of the eutrophication problems in the Baltic Sea is based on a balance between sources and sinks, we cannot ignore the atmospheric deposition of phosphorus. Phosphorus deposition data are generally rather scarce and fragmentary. For Northern Europe the levels are found to be in the range of $5-40 \mathrm{~kg} \mathrm{P}$ $\mathrm{km}^{-2}$ year $^{-1}$ (Anttila et al. 1995; Pollman et al. 2002; Ellermann et al. 2003; Savchuk 2005 and references therein; Mahowald et al. 2008; Rolff et al. 2008). In the absence of more detailed information, we assumed in our reconstruction $15 \mathrm{~kg} \mathrm{P} \mathrm{km}^{-2}$ year $^{-1}$ to have been invariably and evenly deposited over the entire Baltic Sea during 1970-2006.

\section{RESULTS AND DISCUSSION}

With the procedure explained in the previous section, we were able to assess the relative changes in the deposition of reduced and oxidized nitrogen and phosphorus compared to 1970 values. In the estimate, the rates of change considerably differ between the components (Table 1), which arises from the different development of the main sources of $\mathrm{NO}_{x}$ and $\mathrm{NH}_{3}$ emissions. For all the components, the increase was estimated to accelerate over time, being strongest for oxidized nitrogen. This is in line with emission scenarios, in which $\mathrm{NO}_{x}$ emissions from traffic and energy production, in particular, have risen exponentially since 1950 (Lamarque et al. 2010; Langner et al. 2010). Likewise, a steeper rise in ammonia emissions from the agricultural sector can be detected after 1950 (Lamarque et al. 2010; Langner et al. 2010). Compared to nitrogen deposition, centennial changes in phosphorus deposition have been less pronounced (Mahowald et al. 2008).

We approached the historical development of nitrogen deposition to the Baltic Sea from a new starting point by combining different information sources in one package: a

Table 1 Rate of deposition of reduced nitrogen (Nred), oxidized nitrogen $\left(\mathrm{NO}_{x}\right)$, and phosphorus $(\mathrm{P})$ compared to 1970 values

\begin{tabular}{llll}
\hline Years & Nred & $\mathrm{NO}_{x}$ & $\mathrm{P}$ \\
\hline 1850 & 0.25 & 0.13 & 0.50 \\
1900 & 0.30 & 0.15 & 0.55 \\
1925 & 0.38 & 0.23 & 0.58 \\
1950 & 0.50 & 0.40 & 0.60 \\
1960 & 0.65 & 0.53 & 0.70 \\
1970 & 1.00 & 1.00 & 1.00 \\
\hline
\end{tabular}


proven component of historical data, recent emission estimates, and gridded deposition time series for contemporary deposition. In particular, the use of the RCP emission estimates was an advantage in the development of the functioning combination, which had not been available earlier. Our factors for the change in the deposition estimates fit rather well with the development in European emissions from 1850 to 2000 . Our study demonstrates an approximately twofold increase in ammonium or nitrate deposition when compared to previous estimates extending to the 1800s (Brimblecombe and Stedman 1982; Asman et al. 1988; Skeffington and Wilson 1988). However, there are clear similarities with the modeled flow of reduced nitrogen deposition at Gårdsjö, Sweden, between 1880 and 2000 (Schöpp et al. 2003). The fit of our results with estimates covering time periods since 1920 (Fagerli et al. 2007) and 1950 (Rodhe and Rood 1986), as well as the nitrate deposition measured at Rothamsted (Fig. S1, Electronic Supplementary Material), is rather good.

Continuous time series of the monthly mean depositions of four nitrogen components (wet and dry deposition of reduced and oxidized nitrogen) and phosphorus were separately generated for each of the 13 Baltic Sea basins for 1850-2006. Figure 3 presents the nitrogen depositions to the Baltic Sea summed over all 13 basins and the seasonal pattern.

When compiling the time series, we assumed that changes in the meteorological parameters affecting $\mathrm{N}$ transport to the Baltic Sea within the past 150 years have not been greater than the year-to-year variation, which was estimated to be $30 \%$ in 1995-2006 (Bartnicki et al. 2011).

There are non-linearities in the atmospheric chemistry of nitrogen and sulfur compounds that might cause uncertainties in our deposition estimates, which have a firm basis in the emission scenarios. The emission-deposition relationship for ammonia changed during the study time period because of the more rapid conversion of gaseous ammonia to ammonium aerosols caused by the higher availability of sulfuric and nitric acid (Fagerli et al. 2007). The average transport distance for ammonium aerosols is longer than that for gaseous ammonia (e.g., Ferm 1998). Thus, after about 1950, a relatively larger proportion of ammonia emissions might have been transported to the Baltic Sea from the dense emission fields. Our time series for reduced nitrogen at least partly captures this temporal change in the non-linearity. After 1950, the estimated deposition of reduced nitrogen increases at a faster rate than ammonia emissions.

Our time series was compiled by estimating the $\mathrm{N}$ deposition at a few reference years and linearly interpolating between them. The influence of climate variability and variation in the circular patterns on the interpolated $\mathrm{N}$ depositions was not taken into account in this method.
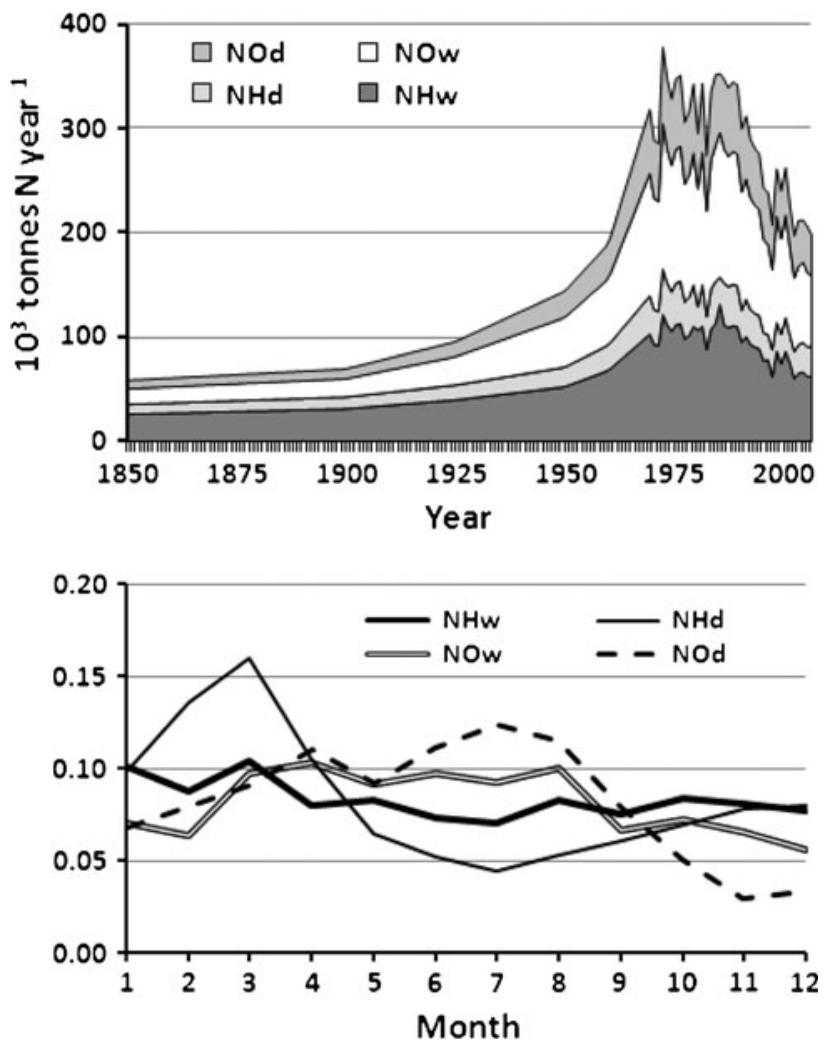

Fig. 3 Annual integrals (kton year ${ }^{-1}$, upper figure) and seasonal patterns (dimensionless monthly fractions of annual integrals, lower figure) of inorganic nitrogen deposition to the entire Baltic Sea in 1850-2006. NHw and NHd wet and dry fractions of reduced nitrogen, NOw and Nod: wet and dry fractions of oxidized nitrogen

European precipitation and wind patterns are important factors in the regional distribution of $\mathrm{N}$ deposition, the former especially for wet deposition and the latter for dry deposition (Andersson et al. 2007). Hole and Enghardt (2008) calculated N deposition to the Baltic Sea area under the future climate and determined that increased westerlies will remove excess oxidized and reduced nitrogen in western Norway and thus reduce $\mathrm{N}$ deposition over large areas of the Baltic Sea by $10-20 \%$ per year. The average inter-annual variation for the components of $\mathrm{N}$ deposition to the Baltic Sea due to meteorological variability was estimated at 5-20\% for a period of 44 years (Andersson et al. 2007) and 5-8\% for a period of 10 years (Langner et al. 2009). Because our method did not enable the accurate calculation of uncertainty in the deposition values, we estimated that climate variability and variations in circulation patterns cause $20 \%$ uncertainty in the values, according to the literature.

When compiling the time series, due to the restricted data available we had to make general assumptions concerning the development of nitrogen emissions and deposition. The assumptions of similar trends in all sub-basins and stable seasonal variation would have required that the 
relative changes in the emission patterns around the Baltic Sea were unchanged, which is not necessarily the case. The principal emission sectors remained the same throughout the period investigated: agriculture for ammonia and transport and energy generation for nitrogen dioxide. In addition, large emission areas for $\mathrm{NO}_{x}$ and $\mathrm{NH}_{3}$ were localized to the southern coast of the Baltic Sea during the period from 1850 to 1990 (Galloway et al. 2004; Lamarque et al. 2010). However, the rate of increase in both nitrate and ammonium deposition was presumably underestimated in the western sub-basins, which receive a larger fraction of their atmospheric load from countries with early intensive farming and traffic (Bartnicki et al. 2011). Respectively, in the eastern and northern sub-basins the deposition was overestimated. The emissions from shipping have recently soared and further confuse the deposition pattern. The annual cycle of the wet deposition of ammonium remained unchanged in the monitoring time series, which spanned over 90 years, but the corresponding nitrate deposition changed over time (Brimblecombe and Stedman 1982). The uncertainties in our time series caused by the factors discussed above remain to be estimated in future atmospheric modeling experiments. However, the primary aim of this time series construction was to provide atmospheric loads for biogeochemical modeling. As sensitivity studies in modeling of the Baltic Sea have indicated a weak response to a decrease in the atmospheric load, a reduction in nitrogen deposition by $17 \%$ resulting in less than a $5 \%$ change in the steady trophic state of the sea (Savchuk and Wulff 2007), our time series can be regarded as applicable in biogeochemical modeling.

\section{CONCLUSIONS}

As demonstrated in this study, the combination of historical measurements of nitrogen deposition, gridded time series for contemporary deposition and recent consistent emission estimates is a valuable tool for reconstructing long-term atmospheric deposition time series. The method used for the present reconstruction is unique. This work provides an essential input to reconstructions of the evolution of the Baltic Sea from pre-industrial to present day conditions and to evaluations and improvements of biogeochemical models for this region.

There are uncertainties in some of our assumptions. We had to rely on historical data, despite the limitations involved in this. However, the gridded deposition values used towards the end of the period have been justified with modern measurements and comparable modeling. Thus, the method used for our construction of the time series, from the end to the beginning via relative changes, is considered to have reduced the risk of major misjudgments.
The largest uncertainty concerns phosphorus, for which all the information used was based on published estimates. Here, we will need help in the future from atmospheric modelers to determine the validity of our assumptions and suggest possible improvements. Altogether, the validity of the created data set for understanding and reconstruction of the biogeochemical cycling in the Baltic Sea might be explored by sensitivity experiments using biogeochemical models.

Our data set is temporally and spatially consistent. The quantitative continuity between the past and contemporary deposition is ensured by the relative changes in deposition compared to 1970 values.

Acknowledgments This study is part of the ECOSUPPORT project (Advanced modeling tool for scenarios of the Baltic Sea ECOsystem to SUPPORT decision making), which is jointly funded within the BONUS + program by the European Commission, the Swedish Environmental Protection Agency (SEPA) and the Finnish Academy of Sciences. The development and maintenance of Nest, BALTSEM, and BED are parts of the BNI core activities funded by the Swedish Ministry of Environment.

\section{REFERENCES}

Andersson, C., J. Langner, and R. Bergström. 2007. Interannual variation and trends in air pollution over Europe due to climate variability during 1958-2001 simulated with a regional CTM coupled to the ERA40 reanalysis. Tellus 59B: 77-98.

Anonymous. 1955-1959. Current data on the chemical composition of air and precipitation. Note. Tellus 8-11. [20 articles].

Anttila, P., P. Paatero, U. Tapper, and O. Järvinen. 1995. Source identification of bulk wet deposition in Finland by positive matrix factorization. Atmospheric Environment 29: 1705-1718. doi:10.1016/1352-2310(94)00367-T.

Asman, W.A.H., B. Drukker, and A.J. Janssen. 1988. Modelled historical concentrations and depositions of ammonia and ammonium in Europe. Atmospheric Environment 22: 725-735.

Backer, H., J.-M. Leppänen, A.C. Brusendorff, K. Forsius, M. Stankiewicz, J. Mehtonen, M. Pyhälä, M. Laamanen, et al. 2010. HELCOM Baltic Sea Action Plan-A regional programme of measures for the marine environment based on the Ecosystem Approach. Marine Pollution Bulletin 60: 642-649.

Bartnicki, J., and S. Valiyaveetil. 2008. Estimation of atmospheric nitrogen deposition to the Baltic Sea in the periods 1997-2003 and 2000-2006. EMEP MSC-W, Summary Report for HELCOM. http://www.helcom.fi/stc/files/Publications/OtherPublications/ EMEP_Estimation_of_atmospheric_N_deposition_\%20to_the_ BS.pdf. Retrieved 11 October 2011.

Bartnicki, J., A. Gusev, W. Aas, H. Fagerli, and S. Valiyaveetil. 2008. Atmospheric supply of nitrogen, lead, cadmium, mercury and dioxines/furanes to the Baltic Sea in 2006. EMEP Centres Joint Report for HELCOM, Technical Report MSC-W 3/2008, Oslo, Norway.

Bartnicki, J., V.S. Semeena, and H. Fagerli. 2011. Atmospheric deposition of nitrogen to the Baltic Sea in the period 1995-2006. Atmospheric Chemistry and Physics Discussion 11: 1803-1934. doi:10.5194/acpd-11-1803-2011. 
Brimblecombe, P., and J. Pitman. 1980. Long-term deposit at Rothamsted, Southern England. Tellus 32: 261-267.

Brimblecombe, P., and D.H. Stedman. 1982. Historical evidence for a dramatic increase in the nitrate component of acid rain. Nature 298: 460-462.

Davidavichiene, L.G., and D.A. Sopauskiene. 1989. Inputs of nitrogen and phosphorus compounds from atmosphere. In Problems of research and modelling of the Baltic Sea ecosystem. Issue 4. Main Tendencies of the Ecosystem's Evolution, ed. I.N. Davidan, and O.P. Savchuk, 112-118. Leningrad: Baltica Project. Hydrometeoizdat (in Russian).

Egnér, H., and E. Eriksson. 1955. Current data on the chemical composition of air and precipitation. Note. Tellus 7: 134-139.

Eilola, K., B.G. Gustafsson, I. Kuznetsov, H.E.M. Meier, T. Neumann, and O.P. Savchuk. 2011. Evaluation of biogeochemical cycles in an ensemble of three state-of-the-art numerical models of the Baltic Sea. Journal of Marine Systems 88: 267-284.

Ellermann, T., O. Hertel, C.A. Skjøth, K. Kemp, and C. Monies. 2003. Atmosfærisk deposition 2002. NOVA 2003. Danmarks Miljøundersøgelser, Faglig rapport fra DMU, nr. 466, Copenhagen, Denmark (in Danish, English summary).

Eriksson, E. 1952. Composition of Atmospheric Precipitation: I. Nitrogen compounds. Tellus 4: 215-232.

Fagerli, H., M. Legrand, S. Preunkert, V. Vestreng, D. Simpson, and M. Cerqueira. 2007. Modeling historical long-term trends of sulfate, ammonium, and elemental carbon over Europe: A comparison with ice core records in the Alps. Journal of Geophysical Research 112: D23S13. doi:10.1029/2006JD00 8044.

Ferm, M. 1998. Atmospheric ammonia and ammonium transport in Europe and critical loads: A review. Nutrient Cycling in Agroecosystems 51: 5-17.

Fowler, D., M. O'Donoghue, J.B.A. Muller, R.I. Smith, U. Dragosits, U. Skiba, M.A. Sutton, and P. Brimblecombe. 2004. A chronology of nitrogen deposition in the UK between 1900 and 2000. Water, Air, \& Soil Pollution: Focus 4: 9-23.

Galloway, J.N., F.J. Dentener, D.G. Capone, E.W. Boyer, R.W. Howarth, S.P. Seitzinger, G.P. Asner, C.C. Cleveland, et al. 2004. Nitrogen cycles: Past, present, and future. Biogeochemistry 70: $153-226$.

Goulding, K.W.T., P.R. Poulton, V.H. Thomas, and R.J.B. Williams. 1986. Atmospheric deposition at Rothamsted, Saxmundham and Woburn experimental stations, England, 1969-1984. Water, Air, and Soil pollution 29: 27-49.

Granat, L., R. Söderlund, and L. Bäcklin. 1977. The IMI Network in Sweden-Present Equipment, Methods and Plans for Improvement. Department of meteorology, University of Stockholm (MISU) \& International meteorological institute in Stockholm (IMI), Report, AC-40, Stockholm, Sweden.

Granat, L. 1978. Sulfate in precipitation as observed by the European atmospheric chemistry network. Atmospheric Environment 12: 413-424. doi:10.1016/0004-6981(78)90225-1.

Granat, L. 2001. Deposition of nitrate and ammonium from the atmosphere to the Baltic Sea. In A systems analysis of the Baltic Sea, ed. F. Wulff, L. Rahm, and P. Larsson, 133-148. New York: Springer.

Gustafsson, B.G., F. Schenk, T. Blenckner, K. Eilola, H.E.M. Meier, B. Müller-Karulis, T. Neumann, T. Ruoho-Airola, et al. 2012. Reconstructing the development of Baltic Sea eutrophication 1850-2006. AMBIO. doi:10.1007/s13280-012-0318-x.

HELCOM. 1987. First Baltic Sea pollution load compilation. Helsinki Commission, Baltic Sea Environment Proceedings 20, Helsinki, Finland.
HELCOM. 1989. Deposition of airborne pollutants to the Baltic Sea area, 1983-1985 and 1986. Helsinki Commission, Baltic Sea Environment Proceedings 32, Helsinki, Finland.

HELCOM. 1993. Second Baltic Sea pollution load compilation. Helsinki Commission, Baltic Sea Environment Proceedings 45, Hamburg, Germany.

HELCOM. 1997. Airborne pollution load to the Baltic Sea 19911995. Helsinki Commission, Baltic Sea Environment Proceedings 69 , Jönköping, Sweden.

HELCOM. 2007. Baltic Sea Action Plan. http://www.helcom.fi/ BSAP/en_GB/intro/. Retrieved 15 October 2011

Hole, L., and M. Enghardt. 2008. Climate change impact on atmospheric nitrogen deposition in northwestern Europe: A model study. AMBIO 37: 9-17.

Lamarque, J.-F., T.C. Bond, V. Eyring, C. Granier, A. Heil, Z. Klimont, D. Lee, C. Liousse, et al. 2010. Historical (1850-2000) gridded anthropogenic and biomass burning emissions of reactive gases and aerosols: Methodology and application. Atmospheric Chemistry and Physics Discussions 10: 49635019. doi:10.5194/acp-10-7017-2010.

Langner, J., T. Klein, and R. Bergström. 2010. Air pollutant emission scenarios for CLEO. Project 1.3. SMHI, Report 1-2010-12-15.

Langner, J., C. Andersson, and M. Enghardt. 2009. Atmospheric input of nitrogen to the Baltic Sea basin: Present situation, variability due to meteorology and impact of climate change. Boreal Environment Research 14: 226-237.

Larsson, U., R. Elmgren, and F. Wulff. 1985. Eutrophication and the Baltic Sea: Causes and consequences. AMBIO 14: 9-14.

Lindfors V., S. Joffre, and J. Damski. 1991. Determination of the wet and dry deposition of sulphur and nitrogen compounds over the Baltic Sea using actual meteorological data. Finnish Meteorological Institute, Contribution No. 4, Helsinki, Finland.

Lindfors, V., S.M. Joffre, and J. Damski. 1993. Meteorological variability of the wet and dry deposition of sulfur and nitrogencompounds over the Baltic Sea. Water, Air, and Soil pollution 66: 1-28. doi:10.1007/BF00477058.

Mahowald, N., T.D. Jickells, A.R. Baker, P. Artaxo, C.R. BenitezNelson, G. Bergametti, T.C. Bond, C. Ying, et al. 2008. Global distribution of atmospheric phosphorus sources, concentrations and deposition rates, and anthropogenic impacts. Global Biogeochemical Cycles 22:GB4026. doi:10.1029/2008GB003240.

Meier, H.E.M., K. Eilola, and E. Almroth. 2011. Climate-related changes in marine ecosystems simulated with a three-dimensional coupled biogeochemical-physical model of the Baltic Sea. Climate Research 48: 31-55.

Meier, H.E.M., B. Müller-Karulis, H.C. Andersson, C. Dieterich, K. Eilola, B.G. Gustafsson, A. Höglund, R. Hordoir, et al. 2012. Impact of climate change on biogeochemical cycles in the Baltic Sea-a multi-model ensemble study. AMBIO. doi:10.1007/ s13280-012-0320-3.

Miller, N.H.J. 1905. The amounts of nitrogen as ammonia and as nitric acid and chlorine in the rainwater collected at Rothamsted. Journal of Agricultural Science 1: 280-303.

Moberg, A., H. Tuomenvirta, and P.Ø. Nordli. 2005. Recent climatic trends. In The physical geography of Fennoscandia, ed. M. Seppälä, 113-133. The Oxford Regional Environments Series. Chippenham, Wilts: Antony Rowe Ltd.

Nehring, D., and A. Wilde. 1982. Untersuchungen über den atmosphärischen Nährstoffeintrag in die Ostsee. Acta Hydrochimica et Hydrobiologica 10: 89-100. doi:10.1002/aheh.19820100117 (in German).

Pollman, C.D., W.M. Landing, J.J. Perry Jr, and T. Fitzpatrik. 2002. Wet deposition of phosphorus in Florida. Atmospheric Environment 36: 2309-2318. doi:10.1016/S1352-2310(02)00199-1. 
Rodhe, H., and M.J. Rood. 1986. Temporal evolution of nitrogen compounds in Swedish precipitation since 1955. Nature 321: 762-764.

Rolff, C., R. Elmgren, and M. Voss. 2008. Deposition of nitrogen and phosphorus on the Baltic Sea: seasonal patterns and nitrogen isotope composition. Biogeosciences 5: 1657-1667. doi: 10.5194/bg-5-1657-2008.

Russell, E.J., and E.H. Richards. 1919. The amounts and composition of rain and snow falling at Rothamsted. Journal of Agricultural Science 9: 309-337.

Savchuk, O.P. 2005. Resolving the Baltic Sea into seven subbasins: N and P budgets for 1991-1999. Journal of Marine Systems 56: 1-15. doi:10.1016/j.jmarsys.2004.08.005.

Savchuk, O.P., and F. Wulff. 2007. Modeling the Baltic Sea eutrophication in a decision support system. AMBIO 36: 141-148.

Savchuk, O.P., and F. Wulff. 2009. Long-term modeling of largescale nutrient cycles in the entire Baltic Sea. Hydrobiologia 629: 209-224.

Savchuk, O.P., F. Wulff, S. Hille, C. Humborg, and F. Pollehne. 2008. The Baltic Sea a century ago-a reconstruction from model simulations, verified by observations. Journal of Marine Systems 74: 485-494

Savchuk, O.P., K. Eilola, B.G. Gustafsson, M. Rodriguez, and T. Ruoho-Airola. 2012. Long-term reconstruction of nutrient loads to the Baltic Sea, 1850-2006. Baltic Nest Institute, BNI Technical Report Series No. 6, Stockholm, Sweden.

Schöpp, W., M. Posch, S. Mylona, and M. Johansson. 2003. Longterm development of acid deposition (1880-2030) in sensitive freshwater regions in Europe. Hydrology and Earth System Sciences 7: 436-446.

Skeffington, R.A., and E.J. Wilson. 1988. Excess nitrogen deposition: Issues for consideration. Environmental Pollution 54: 159-184.

Sutton, M.A., J.W. Erisman, F. Dentener, and D. Möller. 2008. Ammonia in the environment: From ancient times to the present. Environmental Pollution 156: 583-604. doi:10.1016/ j.envpol.2008.03.013.

\section{AUTHOR BIOGRAPHIES}

Tuija Ruoho-Airola $(\square)$ is a senior scientist at the Finnish Meteorological Institute (FMI). She holds a $\mathrm{PhD}$ in environmental sciences from the University of Helsinki. Her professional interest is atmospheric concentration and deposition of inorganic pollutants with focus on data analysis of spatial and temporal changes. She is also involved in various environmental assessment programs and longterm monitoring.

Address: Air Quality Research, Finnish Meteorological Institute, P.O. Box 503, 00101 Helsinki, Finland.

e-mail: tuija.ruoho-airola@fmi.fi

Kari Eilola is an oceanographer and senior scientist at the department of research and development at the Swedish Meteorological and Hydrological Institute (SMHI). His research interests include physical and biogeochemical modeling of the Baltic Sea.

Address: Swedish Meteorological and Hydrological Institute, Sven Källfelts gata 15, 42671 V Frölunda, Sweden.

e-mail: kari.eilola@smhi.se

Oleg P. Savchuk graduated from the Leningrad State University in 1971 as oceanographer. Since then he uses mathematical modeling as a tool to study marine ecosystems of the Baltic, White, Barentz, and North seas, with emphasis on nutrient biogeochemical cycles.

Address: Baltic Nest Institute, Stockholm University, 10691 Stockholm, Sweden.

e-mail: oleg@ecology.su.se

Maija Parviainen is an information specialist at the Finnish Meteorological Institute.

Address: Air Quality Research, Finnish Meteorological Institute, P.O. Box 503, 00101 Helsinki, Finland.

e-mail: maija.parviainen@fmi.fi

Virpi Tarvainen has a PhD in Physics from the University of Helsinki and is a Senior Research Scientist at the Finnish Meteorological Institute. Her research interests include modeling of biogenic emissions and atmospheric chemistry.

Address: Air Quality Research, Finnish Meteorological Institute, P.O. Box 503, 00101 Helsinki, Finland.

e-mail: virpi.tarvainen@fmi.fi 